Vol. 5, No. 1, Juni 2020, pISSN 2527-2853, eISSN 2549-2985

\title{
Studi Aplikasi Corporate Identity Pada Elemen Interior Kantor Telkom Indonesia
}

\author{
M. Togar Mulya Raja ${ }^{1}$, Vika Haristianti ${ }^{2}$, Dennisa Yori Ananda ${ }^{3}$ \\ Fakultas Industri Kreatif, Universitas Telkom \\ togarmulyaraja@telkomuniversity.ac.id' ${ }^{1}$, haristiantivika@telkomuniversity.ac.id², dennisayori@gmail.com ${ }^{3}$
}

\begin{abstract}
ABSTRAK
Identitas korporat merupakan salah satu faktor penting dalam membangun citra diri sebuah perusahaan. PT. TELKOM merupakan salah satu perusahaan besar di Indonesia yang sangat berhasil membangun sebuah citra perusahaan. PT. TELKOM memiliki citra yang sudah sangat melekat dan mudah dikenali oleh masyarakat luas. Identitas korporat juga merupakan aspek penting dalam perancangan interior, dengan tujuan untuk membuat para pengguna ruang memahami citra dari perusahaan melalui implementasi dalam setiap elemen interior. Penelitian ini mengkaji beberapa kantor PT. TELKOM yang cukup signifikan mengimplemtasikan identitas korporat dalam elemen interiornya. Kata kunci: Identitas korporat; Kantor Telkom Indonesia; Elemen interior
\end{abstract}

\section{ABSTRACT}

Corporate identity is one of the important factor in building a company's self-image. PT. Telkom is one of the big companies in Indnonesia that has been very successful in building a corporate image. PT. Telkom has an image that is already very attached and easily recognized by the wider community. Corporate identity is also an important aspect in interior design, with the aim of making space users understand the image of the company through implementation in every interior element. This study examines several office of PT. Telkom, which quite significantly implements corporate identity in its interior elements.

Keyword: Corporate identity; Telkom Indonesia Office; Interior element

\section{PENDAHULUAN}

Perkembangan dalam bidang teknologi informasi dan telekomunikasi saat ini sangat pesat, dan memberikan dampak baik positif maupun negatif pada kehidupan sehari-hari. Teknologi tersebut menjadi kebutuhan penting agar selalu membuat setiap orang menjadi saling terhubung. Sehubungan dengan perkembangan teknologi informasi dan telekomunikasi terutama di Indonesia dikenal salah satu badan usaha yang terbesar di bidang teknologi informasi dan telekomunikasi yaitu Telkom Indonesia. Telkom Indonesia merupakan Badan Usaha Milik Negara (BUMN) yang memiliki jangkauan merata hampir di seluruh wilayah negeri. Daya jangkau Telkom Indonesia yang sangat luas tersebut membuat Telkom Indonesia perlu membuat cabang dalam bentuk kantor agar disitribusi jasa lebih efektif. Gedung perkantoran Telkom Indonesia tersebar pada setiap wilayah di Indonesia, mulai dari tingkatan regional, wilayah setiap provinsi, kota, sampai dengan kecamatan. Hal tersebut menunjukkan bahwa Telkom Indonesia menjadi salah satu perusahaan terbesar di Indoneisa.

Besarnya Telkom Indonesia tidak lepas dari citra perusahaan yang sudah sangat kental dan dikenal oleh masyarakat Indonesia. Citra perusahaan yang telah dibangun bertahun-tahun membuat Telkom Indonesia juga sangat dikenal dan hampir mendominasi dalam bidang teknologi informasi dan telekomunikasi. Identitas korporat bertujuan untuk masyarakat secara umum agar lebih sadar dengan eksistensi Telkom Indonesia, tetapi selain itu ditujukan untuk menunjukkan Telkom Indonesia sendiri kepada para staff-nya. Identitas korporat dapat disampaikan kepada staff melalui budaya kerja, serta lebih mudahnya adalah melalui aspek 
visual. Aspek visual tersebut salah satunya adalah warna yang identik dengan Telkom Indonesia. Warna identitas Telkom Indonesia tersebut dapat diaplikasikan pada elemen interior kantor Telkom Indonesia. Penelitian ini bertujuan untuk melihat sejauh apa implementasi identitas korporat dari Telkom Indonesia pada beberapa kantor Telkom Indonesia. Masalah yang muncul adalah tidak semua kantor Telkom Indonesia mengaplikasikan identitas Telkom Indonesia pada elemen interiornya, sehingga citra perusahaan tidak terlalu tampak pada interior kantor Telkom Indonesia.

\section{METODE PENELITIAN}

Metode penelitian menggunakan kualitatif deskriptif dengan melakukan studi komparasi dari beberapa studi kasus kantor Telkom Indonesia, yaitu Telkom Indonesia Divre 3 Jawa Barat, Telkom Indonesia Divre 2 DKI Jakarta, dan Telkom Indonesia Divre 4 Jawa Tengah. Hasil dari penelitian diambil sebuah kesimpulan mengenai seberapa banyak implementasi dan aplikasi pada setiap elemen interior pada kantor Telkom Indonesia yang dijadikan studi kasus.

\section{A. Metode Pengumpulan Data}

Metode pengumpulan yang digunakan adalah metode observasi langsung pada ketiga studi kasus dan melakukan dokumentasi. Data tersebut akan digunakan selanjutnya untuk dilakukan analisis dengan cara komparasi.

\section{B. Analisis Data}

Analisis data dilakukan setelah proses pengamatan atau observasi yang dilakukan langsung pada studi kasus yaitu kantor-kantor Telkom Indonesia dari tiga daerah yang berbeda. Data yang didapat kemudian diolah dan dianalisis lebih lanjut dengan menggunakan tabel komparasi. Variabel yang digunakan adalah jenis elemen interior yaitu lantai, dinding, plafond dan furnitur.

\section{HASIL PENELITIAN DAN PEMBAHASAN}

\section{A. Kajian literature}

\section{Corporate Identity}

Corporate identity merupakan citra dari sebuah perusahaan yang dapat disampaikan dan terlihat melalui bentuk visual. Corporate identity menurut Anggoro (2000:280) adalah suatu cara atau suatu hal yang memungkinkan suatu perusahaan dikenal dan dibedakan dari perusahaan-perusahaan lainnya. Dalam bukunya kemudian disebutkan bahwa identitas tersebut harus diciptakan dengan desain khusus dan bersangkutan secara fisik. Kasali (2003:110-114) menyebutkan bahwa identitas perusahaan atau identitas korporat disebut juga sebagai simbol perusahaan, apakah berbentuk logo perusahaan atau lambang lainnya. Simbol dimaksud agar lebih mudah diingat oleh konsumen juga agar lebih dijiwai oleh semua karyawannya. Simbol sangat penting bagi perusahaan yang bergerak di sektor jasa untuk menjaga pelayanan, kredibilitas dan keramahan didalamnya. Corporate identity harus tampak secara visual lebih dijelaskan lagi oleh Selame dalam Sutojo (2004:13), yang mengatakan bahwa identitas korporat adalah apa yang senyatanya ada pada atau ditampilkan oleh perusahaan. Maka dapat dilihat bahwa identitas korporat atau corporate identity merupakan hal-hal yang nyata dan dapat secara visual langsung bisa dirasakan. Salah satu jenis dari corporate identity adalah warna perusahaan yang merupakan bagian dari corporate visual. Corporate visual adalah segala jenis identitas perusahaan yang tampak dalam bentuk visual, misalanya logo, seragam, ataupun warna dari perusahaan itu sendiri 


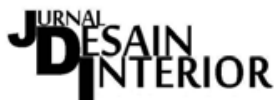

Vol. 5, No. 1, Juni 2020, pISSN 2527-2853, eISSN 2549-2985

Hubungan corporate identity dengan desain interior

Menurut Oylum (2010) dalam jurnal Dagli (2015), desain interior merupakan komponen penting dalam corporate identity, karena desain interior adalah penampang secara visual secara langsung dari corporate identity. Desain interior adalah bentuk dari corporate architecture yang dapat langsung dilihat melalui tata letak ruang, pemilihan warna, furnitur, dan lainnya. (Gagliardi, 1991).

Salah satu contoh perusahaan yang menerapkan citra perusahaan (corporate identity) secara menyeluruh adalah kantor Google. Berikut adalah contoh gambar kantor Google yang telah menerapkan citra perusahaan mereka pada elemen interior sehingga memiliki ciri khas dan identitas.

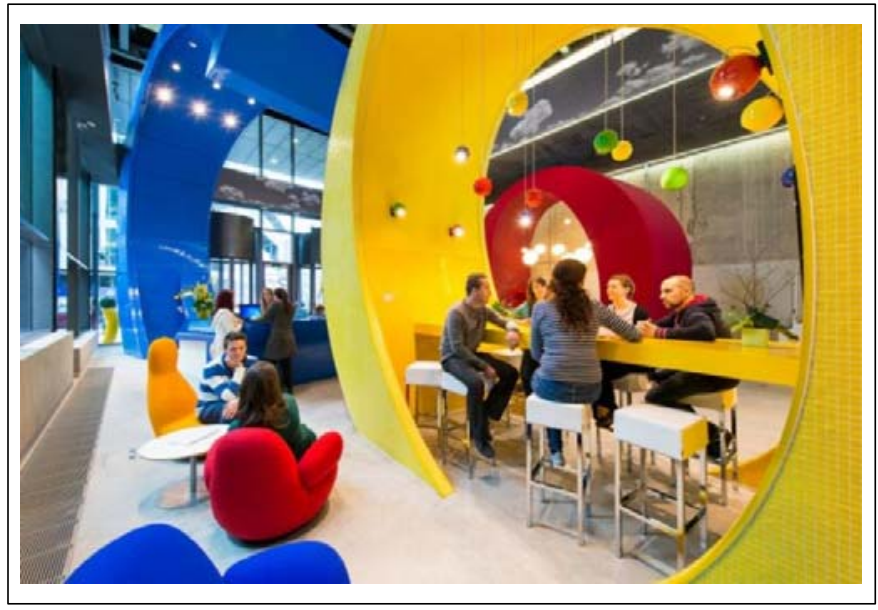

Gambar 1. Interior Kantor Google Sumber: www.adipsi.org/galleryl-google-office.html

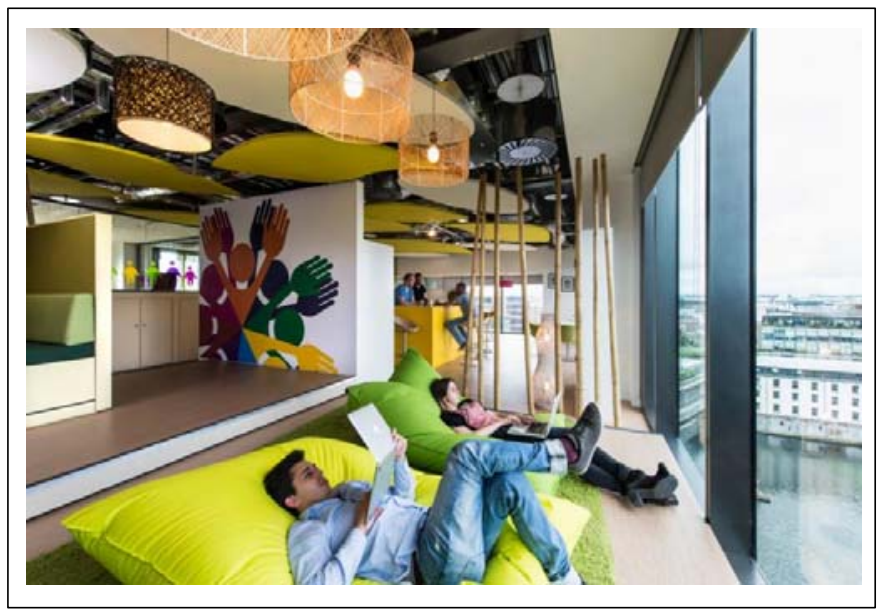

Gambar 2. Interior Kantor Google Sumber: www.adipsi.org/gallery1-google-office.html 


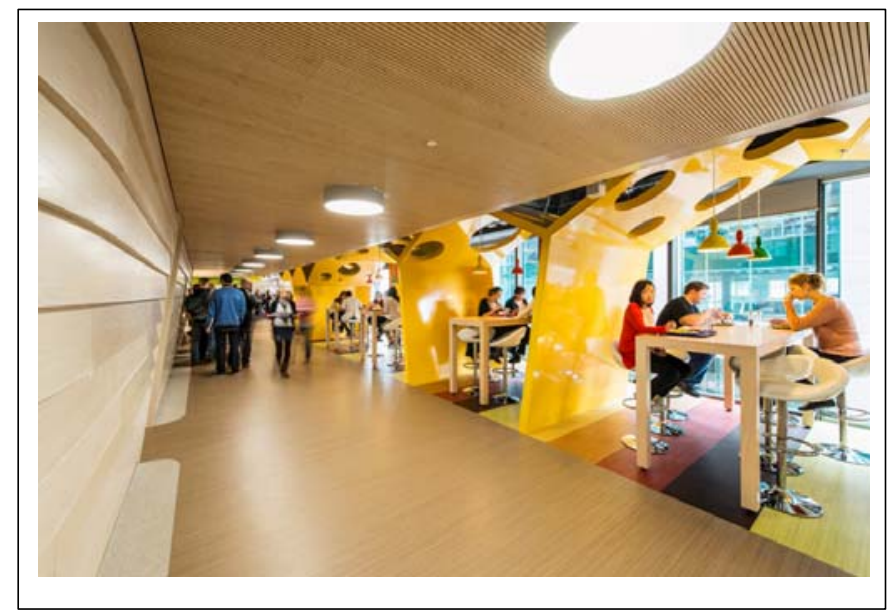

Gambar 3. Interior Kantor Google

Sumber: www.cdn.home-designing.com/wp-content/uploads/2013/01/google-digs-pics

Gambar diatas merupakan contoh implementasi warna identitas perusahaan pada elemen interior yang menyeluruh, sehingga identitas perusahaan akan lebih jelas tanpa harus memberikan logo perusahaan pada elemen interior.

\section{Elemen pembentuk ruang}

Menurut Wicaksono dan Tisnawati (2014), apabila salah satu diantaranya tidak ada maka tidak bisa dianggap sebagai interior. Elemen pembentuk tersebut antara lain:

1. Lantai sebagai batas bawah

2. Dinding sebagai batas vertikal atau penyekat

3. Plafon sebagai bidang atas

4. Berbagai bukaan yang dapat diaplikasikan ke dalam tiga bidang dimensional

5. Elemen pengisi ruang yang dapat berupa furnitur.

Elemen pembentuk ruang yang dijadikan variabl dalam penelitian ini adalah lantai, dinding, plafon, dan furnitur, dimana batasan dari aplikasi corporate identity melalui aplikasi warna perusahaan yang dijadikan studi kasus.

\section{Profil Logo Telkom Indonesia}

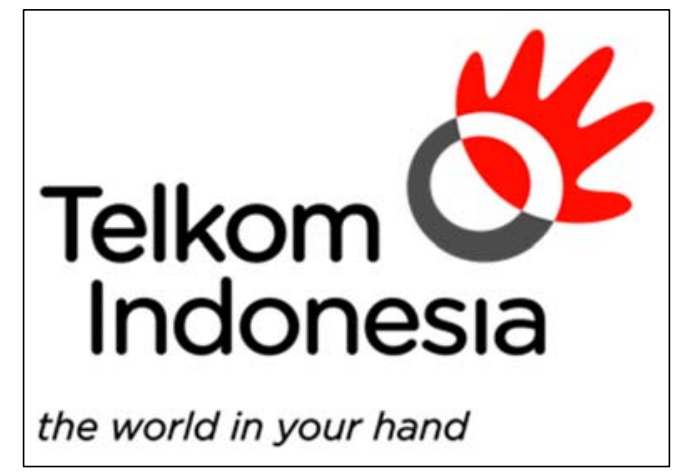

Gambar 4. Logo Telkom Indonesia

Sumber: Telkom.co.id 
Tabel 1. Skema Warna Logo Telkom Indonesia

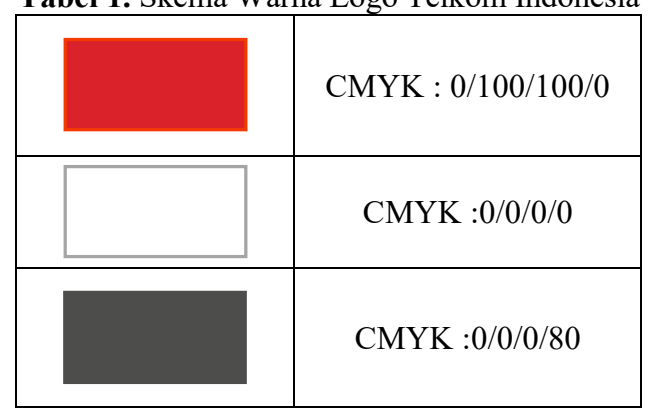

Sumber: studentstelkomuniversity.com

Filosofi warna merah yang berarti berani, cinta, energy, ulet dan mencerminkan spirit perseroan untuk selalu optimis dan berani dalam menghadapi tantangan. Putih berarti suci, damai, cahaya, bersatu dan mencerminkan semangat Telkom untuk memberikan yang terbaik bagi bangsa. Hitam merupakan warna dasar melambangkan kemauan keras. Abu sebagai warna transisi melambangkan teknologi.

\section{B. Analisis}

\section{Studi Kasus}

1. Telkom Indonesia Divisi Regional 3 Area Jawa Barat, berada di Jl. W.R. Supratman No. 66 A, Bandung.

2. Telkom Indonesia Divisi Regional 2 DKI Jakarta, Graha Merah Putih Jakarta, Jl. Jenderal Gatot Subroto, No.52, Jakarta Selatan

3. Telkom Indonesia Divisi Regional 4 Jawa Tengah, Jl. Pahlawan No.10, Semarang, Jawa Tengah.

Dari ketiga studi kasus tersebut akan dibuat tabel komparasi spesifik mengenai implementasi dan aplikasi corporate identity melalui warna Telkom Indonesia pada elemen interior pembentuk ruang.

Tabel 2. Tabel komparasi studi aplikasi warna corporate identity pada elemen interior

\begin{tabular}{|c|c|c|c|}
\hline Elemen & $\begin{array}{c}\text { Telkom Indonesia } \\
\text { Divre } 3 \text { Jawa Barat }\end{array}$ & $\begin{array}{c}\text { Telkom Indonesia } \\
\text { Divre } 2 \text { DKI Jakarta }\end{array}$ & $\begin{array}{c}\text { Telkom Indonesia } \\
\text { Divre } 4 \text { Jawa Tengah }\end{array}$ \\
\hline \multicolumn{4}{|l|}{ Plafon } \\
\hline & $\begin{array}{c}\text { Pengolahan citra } \\
\text { perusahaan: Ya, } \\
\text { berdasarkan } \\
\text { pengolahan warna dan } \\
\text { bentuk dari plafon. }\end{array}$ & $\begin{array}{c}\text { Pengolahan citra } \\
\text { perusahaan: Tidak. } \\
\text { Tidak ada pengolahan } \\
\text { warna, bentuk yang } \\
\text { dapat mewakili citra dari } \\
\text { perusahaan. }\end{array}$ & $\begin{array}{c}\text { Pengolahan citra } \\
\text { perusahaan: Ya } \\
\text { Ada pengolahan dari } \\
\text { bentuk pada plafon dan } \\
\text { warna yang digunakan } \\
\text { kombinasi putih dan } \\
\text { abu-abu. }\end{array}$ \\
\hline
\end{tabular}




\begin{tabular}{|c|c|c|c|}
\hline Elemen & $\begin{array}{c}\text { Telkom Indonesia } \\
\text { Divre } 3 \text { Jawa Barat }\end{array}$ & $\begin{array}{c}\text { Telkom Indonesia } \\
\text { Divre } 2 \text { DKI Jakarta }\end{array}$ & $\begin{array}{c}\text { Telkom Indonesia } \\
\text { Divre } 4 \text { Jawa Tengah }\end{array}$ \\
\hline \multicolumn{4}{|l|}{ Dinding } \\
\hline & $\begin{array}{c}\text { Pengolahan citra } \\
\text { perusahaan: Ya, } \\
\text { pemilihan warna khas } \\
\text { perusahaan. }\end{array}$ & $\begin{array}{l}\text { Pengolahan citra } \\
\text { perusahaan: Ya, hanya } \\
\text { melalui mural visi misi } \\
\text { perusahaan, bukan } \\
\text { warna atau bentuk. }\end{array}$ & $\begin{array}{c}\text { Pengolahan citra } \\
\text { perusahaan: Mural visi } \\
\text { dan misi perusahaan. }\end{array}$ \\
\hline \multicolumn{4}{|c|}{ Wanla diau Demluk. } \\
\hline & $\begin{array}{l}\text { Pengolahan corporate } \\
\text { identity: Tidak } \\
\text { Belum ada pengolahan } \\
\text { bentuk ataupun warna } \\
\text { pada elemen lantai. }\end{array}$ & $\begin{array}{l}\text { Pengolahan corporate } \\
\text { identity: Tidak } \\
\text { Pengolahan elemen } \\
\text { lantai hanya pola dan } \\
\text { berwarna kontras, tetapi } \\
\text { masih belum mencirikan } \\
\text { corporate identity. }\end{array}$ & $\begin{array}{l}\text { Pengolahan corporate } \\
\text { identity: Tidak } \\
\text { Pengolahan elemen } \\
\text { lantai hanya pola dan } \\
\text { berwarna kontras, } \\
\text { tetapi masih belum } \\
\text { mencirikan corporate } \\
\text { identity. }\end{array}$ \\
\hline \multicolumn{4}{|l|}{ Furnitur } \\
\hline & $\begin{array}{l}\text { Warna furnitur hanya } \\
\text { menggunakan warna- } \\
\text { warna netral seperti } \\
\text { putih, hitam, dan } \\
\text { elemen kayu. Sehingga } \\
\text { belum terlalu tampak } \\
\text { implementasi } \\
\text { corporate identity dari } \\
\text { pengolahan warna. }\end{array}$ & $\begin{array}{c}\text { Furnitur sedikit } \\
\text { mengimplementasikan } \\
\text { warna dari corporate } \\
\text { identity, yang tampak } \\
\text { pada warna kuris yang } \\
\text { digunakan yaitu warna } \\
\text { merah. Sedangkan } \\
\text { furnitur lain masih sama } \\
\text { hanya menggunakan } \\
\text { warna netral yaitu hitam } \\
\text { dan putih. }\end{array}$ & $\begin{array}{c}\text { Elemen furnitur } \\
\text { menggunakan warna } \\
\text { biru yang merupakan } \\
\text { warna dari corporate } \\
\text { identity yang sudah } \\
\text { lama. }\end{array}$ \\
\hline
\end{tabular}

Sumber: Hasil analisis (2019) 
Pembahasan aplikasi corporate identity dalam elemen interior Kantor Telkom Indonesia

Penelitian ini dibatasi pada implementasi dan aplikasi citra perusahaan (corporate identity) dalam aspek warna pada elemen interior yang dibatasi pada lantai, dinding, plafon, dan furniture. Berdasarkan tabel analisis diatas dapat dilihat bahwa kantor yang banyak mengimplementasikan dan mengaplikasikan aspek warna dari corporate identity adalah Kantor Telkom Indonesia Divre 3 Jawa Barat. Fakta yang berbeda tampak pada Kantor Telkom Indonesia Divre 2 DKI Jakarta tidak banyak mengimplementasikan aspek warna dari citra perusahaan, aplikasi warna hanya digunakan dari beberapa fasilitas duduk kantor, sedangkan pada Kantor Telkom Indonesia Divre 4 Jawa Tengah, implementasi hanya pada lobi, sedangkan hal yang berbeda tampak pada area kerja dimana masih mengaplikasikan warna biru. Jika diaitkan berdasarkan citra perusahaan, warna biru adalah warna dari Telkom Indonesia yang sudah tidak lagi digunakan.

Berdasarkan komposisi warna yang ada, warna yang sekarang dominan digunakan untuk citra Telkom Indonesia adalah warna merah, sedangkan warna putih dan abu biasa digunakan untuk elemen penunjang atau sebagai warna aksentuasi. Telkom Indonesia identik dengan warna merah. Secara visual ketiga studi kasus tidak banyak menggunakan warna dominan merah pada setiap ruangan.

\section{KESIMPULAN}

Jika merujuk dari literatur, bahwa penting untuk mengaplikasikan citra perusahaan pada elemen interior sebuah kantor agar identitas perusahaan lebih dapat dibangun. Berdasarkan hasil analisa dan pembahasan maka dapat dikatakan bahwa Kantor Telkom Indonesia, baik Jawa Barat, DKI Jakarta, dan Jawa Tengah belum secara total menerapkan aspek warna citra perusahaan Telkom Indonesia pada elemen interior. Penerapan hanya pada beberapa ruang, sehingga tidak terlalu tampak identitas perusahaan pada beberapa ruang.

Berdasarkan literatur bahwa citra perusahaan baiknya diaplikasikan pada elemen interior agar dapat terlihat secara visual. Melihat kondisi eksisting ketiga kantor ini maka dapat lebih menerapkan citra perusahaan secara lebih menyeluruh agar identitas perusahaan lebih tampak baik secara visual maupun non visual.

\section{DAFTAR PUSTAKA}

Anggoro, M. L. (2000). Teori dan Profesi Kehumasan serta Aplikasinya di Indonesia. Jakarta: Bumi Aksara.

Dagli, Zeynep. (2016). Corporate identity in interior design. Global Journal on Humanities and Social Sciences.

Gagliardi, P. (Ed.). (1990). Symbols and Artifacts. New York: Routledge

Kasali, R. (1994). Manajemen Public Relations: Konsep dan Aplikasinya di Indonesia. Jakarta: Pustaka Utama Grafiti.

Sutojo, S. (2004). Membangun Citra Perusahaan. Jakarta: PT. Damar Mulia Pustaka

Wicaksono, A. A., \& Tisnawati, E. (2014). Teori interior. Griya Kreasi. 
M. Togar Mulya Raja, Vika Haristianti, Dennisa Yori Ananda

Studi Aplikasi Corporate Identity Pada Elemen Interior Kantor Telkom Indonesia 